\title{
A CASE STUDY OF VIBRATION FAULT DIAGNOSIS APPLIED AT ROLLS-ROYCE T-56 TURBOPROP ENGINE
}

\author{
Christos SKLIROS \\ Integrated Vehicle Health Management, School of Transport, Manufacturing and Aerospace, \\ Cranfield University, Bedfordshire, United Kingdom
}

Received 31 October 2019; accepted 23 December 2019

\begin{abstract}
Gas turbine engines include a plethora of rotating modules, and each module consists of numerous components. A component's mechanical fault can result in excessive engine vibrations. Identification of the root cause of a vibration fault is a significant challenge for both engine manufacturers and operators. This paper presents a case study of vibration fault detection and isolation applied at a Rolls-Royce T-56 turboprop engine. In this paper, the end-to-end fault diagnosis process from starting system faults to the isolation of the engine's shaft that caused excessive vibrations is described. This work contributes to enhancing the understanding of turboprop engine behaviour under vibration conditions and highlights the merit of combing information from technical logs, maintenance manuals and engineering judgment in successful fault diagnosis.
\end{abstract}

Keywords: gas turbines, vibration, diagnostics, condition-based maintenance, fault detection, fault isolation.

\section{Introduction}

An accurate system's health diagnosis is vital in enhanced safety and optimisation of maintenance planning. Condition-based maintenance is a capability that enables organisations to optimise their maintenance strategies of complex assets and, ultimately, their project and business plans (Vachtsevanos et al., 2006; Jennions, 2011). Maintenance costs contribute significantly to an organization's total cost (Mobley, 2002; Evan, 2012). Thus, there is a profound interest of organisations utilising complex assets to accurately diagnose their asset's health state. Due to the aforementioned background, there have been developed various diagnostic techniques, based on Model-Based (De Kleer \& Kurien, 2003; Hwang et al., 2010), Data-Driven (Gao et al., 2017; Muhammad et al., 2016) and Expert Systems (Durkin, 1994).

In many applications, from an operator's point of view, the main focus of a fault diagnosis strategy is initially to detect a fault in the system and, subsequently, to identify the component that should be replaced to restore the system to the healthy state. This perspective targets minimising downtime due to faults and is especially beneficial for industrial assets whose downtime is expensive. Another primary consideration in fault diagnosis of complex sys- tems is the fact that a component's fault can be revealed by another component's failure. This paper presents an example of this case, where a shaft's fault at a turboprop engine provoked a failure at the engine's pneumatic starter and flexible bleed air tube. Thus, the root cause of the shaft's fault was not readily observed due to the complexity of the system. In order to deal with this danger, regardless of the nature of the diagnostic algorithms used, a diagnostic analysis should be conducted on a system level, considering components interconnections.

This work describes a case study of vibration fault diagnosis at a Rolls-Royce T-56 engine. The engine's main components are illustrated in Figure 1. The aim of this paper is to present the steps followed by the observation

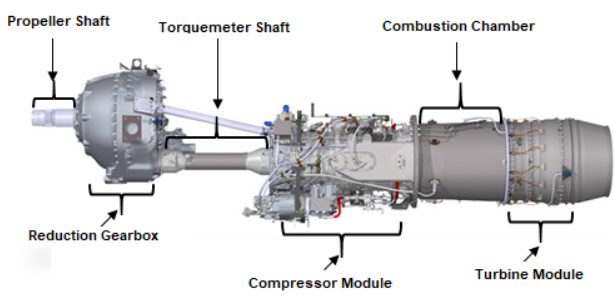

Figure 1. The main components of turboprop engine T-56

${ }^{*}$ Corresponding author. E-mail: c.skliros@cranfield.ac.uk 
of fault symptoms until the faulty module is identified. The main objective is the discussion of maintenance actions and decisions taken through this process. The major step forward is that fault isolation went beyond the steps suggested in the Fault Isolation Manual (FIM). Decisions for fault diagnosis were based on a combination of FIM, maintenance logs, and engineering judgment. This case study refers to a legacy engine model, and conclusions can be generalised to similar applications. This work does not target suggesting an algorithm for capturing engine vibrations. The main emphasis is given in presenting the way vibration fault symptoms are observable from a technician's point of view, and the reasoning followed to proceed to maintenance actions, based on the sensor information that can be extracted from a legacy system.

\section{State-of-art}

\subsection{T-56 Engine background}

The turboprop is a gas turbine engine that drives a propeller. The design and development of turboprop engines started in the early '20s and through the years, and it has been widely used in many aircrafts. Propulsion offered by turboprop engines is mainly generated by the propeller rather than the exhaust gases reaction (Jackson, 1997; Walsh \& Fletcher, 2004).

In this paper, a vibration fault diagnosis case study is conducted on a Rolls-Royce T-56 engine operated at a military cargo aircraft. T-56 operates at a constant rotational speed and drives a variable pitch propeller, and the fuel flow is controlled by a hydro-mechanical fuel control unit. Figure 1 illustrates the T-56 configuration. T-56 is a single shaft engine, and it consists of a propeller which is mounted on a reduction gearbox. Mechanical energy is transmitted to the gearbox from the gas turbine through a torque meter shaft. The gas turbine which drives the torque meter shaft consists of a 14-stage axial compressor followed by a 6-can annular combustion chamber and a 4-stage axial turbine.

A pneumatic starter mounted on the reduction gearbox is used to initiate the starting process. Bleed air generated by another operating engine or by the Auxiliary Power Unit is directed through the aircraft's high-pressure bleed air ducting to a pressure regulating valve (starter control valve). After the bleed air pressure has been regulated at a level that satisfies the starter's safe limits, it enters the pneumatic starter. Figure 2 presents the sequence of components directing bleed air from the aircraft's bleed air system to the pneumatic starter. The pneumatic starter engages with the gearbox by a clutch assembly and disengages at approximately $60 \%$ of nominal engine speed (Hungate, 1979).

\subsection{Vibrations fault detection techniques}

Vibration faults diagnostics is an active field of research since it is of great interest to both operators and manufacturers. Public domain literature dedicated to vibration fault diagnosis is vast. This brief literature survey targets in gleaning the most representative ideas and techniques used to approach this issue. Detailed analysis of the presented methodologies and algorithms would increase the length of the paper significantly and would deviate from the scope of this work.

Source of a vibration fault can be a mechanical fault of a component of a rotating module. Some characteristic examples are cracks of bearings, shaft misalignment, unbalanced compressor or turbine modules, non-uniform degradation of compressor, or turbine blades (Cubillo, Perinpanayagam, \& Esperon-Miguez, 2016). The main targets of vibration fault diagnosis strategies aim in detecting vibration faults at initial stages and identifying the fault's root cause. In order to achieve this, appropriate velocity or acceleration signals are captured from various locations of the system under investigation (Milne et al., 2018; Teng et al., 2016). Locations of mounting signal transducers are specified by the system's manufacturer. Modern system designs have embedded vibration transducers targeted to capture abnormal signals while the system is operating.

The acquired signals are analysed using signal processing algorithms. The most popular algorithms used are Fast Fourier Transformation (Mirsaitov \& Ignatkov, 2018; Teng et al., 2016; Djaidir et al., 2017; Nivesrangsan, 2018; Silva et al., 2018) and Wavelet transformation (Fedoronchak \& Kolpakova, 2018; Jia et al., 2018; Cubillo et al., 2016; Hu et al., 2018; Haidong et al., 2018; Teng et al., 2016; Silva et al., 2018) The final assessment of the fault detection, component identification, or degradation severity has been achieved using artificial intelligence algorithms,

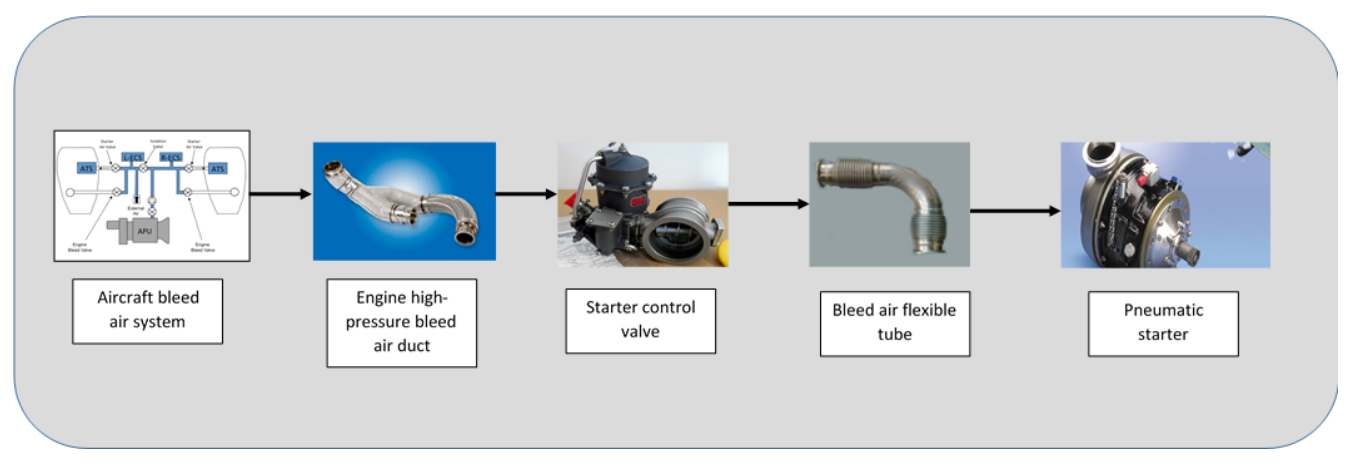

Figure 2. Engine bleed air and starting system components 
such as machine learning (Hu et al., 2018; Jia et al., 2018) or model-based methods (Cubillo, Perinpanayagam, \& Esperon-Miguez, 2016; Saha \& Vachtsevanos, 2006).

An interesting finding in this literature survey is that most of the research conducted in this area concentrates at isolated components (e.g. bearings, gear components in a gearbox or shafts). Providing a few examples, in Teng et al. (2016) fault detection in a wind turbine's gearbox is conducted by analysing accelerometer signals using wavelet transformation. In Nivesrangsan (2018), a ball bearing vibration analysis is undertaken using the Fourier transform. Holistic case studies of systems in service is an issue not sufficiently discussed (Djaidir et al., 2017).

\section{Engine fault investigation}

The symptoms that indicated excessive engine vibrations were related with faults in the starting system components. The initial symptom occurred during an engine start attempt when the engine did not crank, and the aircraft's mission was cancelled. The maintenance personnel followed the instructions in the Fault Isolation Manual (FIM) corresponding to "failure to start" and replaced the engine's starter which restored the engine to operational condition. However, after three engine ignition cycles, another unsuccessful start attempt occurred. This was an identical fault where the engine could not crank and, as in the previous case, the maintenance action that restored the engine to the operating condition was the replacement of the pneumatic starter.

Finally, after five engine ignitions, the engine could not crank. After a visual inspection, the flexible tube connecting the starter control valve with the starter was found to be broken. The latter observation was the third fault in a short period of time that was related to the starting system. Therefore, it was concluded that there existed a more fundamental fault that had not been detected that caused the failures of the starter and the flexible tube. The FIM did not provide any guidance for this phenomenon, so the fault detection and isolation process after that point was based on engineering reasoning of the engine's operation and architecture.

Initially, a fault at the starter control valve was suspected. It was assumed that the starter control valve could not regulate the bleed air pressure, and this resulted in bleed air entering the flexible tube and the pneumatic starter at an excessive pressure. In order to test the starter control valve, dry motoring of the engine was conducted and the starter control valve outlet pressure was measured. The results of the starter control valve test proved that the valve regulates the bleed air pressure correctly and dispatches bleed air at the appropriate pressure to both the flexible tube and the pneumatic starter.

Since the underlying fault was not in the bleed air system, the engine's structural integrity was suspected. Excessive engine vibrations were the next most probable cause of the repeated component failures. Excessive vibrations are related to a fault in one of the main rotating modules: propeller, gearbox, torque meter shaft, compressor, and turbine. The referred components consist of many parts that can be responsible for generating excessive vibrations. For example, the compressor module consists of many rotating blades, bearings, and a shaft. However, maintenance actions applicable to base maintenance capabilities are resultant from a replacement of each one of the main modules. Thus, fault detection and isolation were focused on isolating the fault to one of the main modules.

\section{Vibration fault isolation and discussion}

The T-56 does not have an in-situ vibration monitoring system. For this reason, in order to trace down the root cause of excessive vibrations, the engine was removed from the aircraft and was installed at a test cell to proceed at the fault isolation stage. Based on the corresponding technical manuals, velocity transducers were installed at three locations to measure engine vibrations for the three main engine's rotating modules: gearbox (horizontal), compressor (horizontal), and turbine (vertical), as illustrated in Figure 3. Peak-to-Peak displacement of the velocity transducer signals was measured for all three locations. Also, the dynamic balance of the propeller was carried out since an unbalanced propeller can be a source of excessive engine vibrations. For the dynamic balancing procedure, a velocity transducer was mounted horizontally at the front side of the gearbox. The tests aimed in investigating if the Peak-to-Peak displacements captured by the velocity transducers are within their respective limitation as reported in the maintenance manual.

An engine run was conducted, and it was observed that the propeller was balanced correctly, and the measurements of the vertical velocity transducer mounted at the turbine were within the safe limit. However, both the measurements of the horizontal velocity transducers installed at the gearbox and the compressor were significantly above their respective safe limits. The same results appeared while operating the engine under a wide range of power outputs. The same test was repeated three times and all tests had identical results.

The findings of the tests verified the initial suspicion that the cause of the repeated starter and flexible tube failures was caused due to excessive engine vibrations. The next challenge was to identify the module that should be replaced to restore the engine to service. Since the propeller was dynamically balanced and the turbine's measurements were within the safe limit, the three remaining modules (gearbox, torque meter shaft, and compressor) were more prone to be responsible for the engine's excessive vibrations.

All three candidate components could cause the vibration fault. In order to identify the degraded module, the suspected modules should be serially replaced until one of them results in an engine free of excessive vibrations. Due to workshop logistics and available spare parts, it was decided to initially replace the torque meter shaft. Following the replacement, the engine was installed at the test 


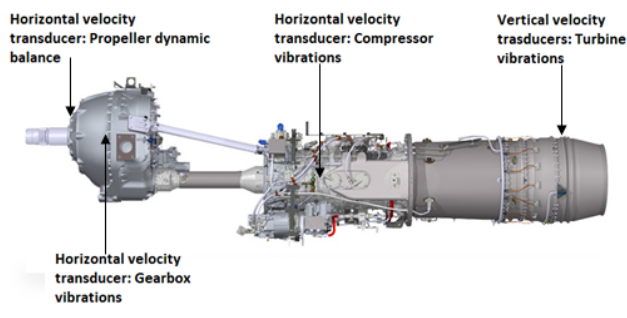

Figure 3. Locations of velocity transducers

cell and vibration readings were collected. Vibrations were monitored, following the same testing process described in the previous paragraph, and all measurements from the velocity transducers were within the safe limits. Based on this outcome, the torque meter shaft was identified as the faulty module that caused excessive vibrations. Table 1 summarises the findings of vibration monitoring on the test cells. The engine was returned to service, and none of the repeated faults (starter failure, flexible tube failure) was observed. This was a final verification of the successful diagnosis of the excessive vibration fault.

One of the main factors that contributed to identifying the repeatability of the faults were the updated maintenance logs. In an organisation in which aircraft operations and maintenance are conducted "around the clock" and by different technicians, the only method to capture fault repeatability is to maintain updated and well-organised maintenance logs. By consulting the maintenance logs, it was possible to identify that the starter and flexible tube faults were an indication of another underlying fault. Fault repeatability is a crucial aspect that should be considered, otherwise an endless loop of replacing the same component will continue. This affects the logistics of an organisation since the flow of outgoing spare parts compared to the flow of incoming will be unbalanced. Also, excessive vibrations can have catastrophic effects and result in an engine breakdown.

The three main elements on which the fault diagnosis process was based are:

1. Keeping updated technical logs and consulting them before conducting maintenance actions

2. Following the procedures described in the technical manuals

3. Engineering reasoning based on the knowledge of the system under examination

Valuable insights can be extracted from this fault event regarding both the engine's behaviour under excessive vibrations as well as maintenance management. Even though identifying the existence of an underlying fault, isolation of the root cause requires domain knowledge of the system under investigation. As presented in section 2 , the engine's faults were initially assumed to be associated with degraded pneumatic starters. A fault in the starter control valve would not affect any other component apart from the starter control valve. For this reason, the fault isolation efforts were directed towards the starter control valve. Finally, since the fault was not related to
Table 1. Vibration test measurement results

\begin{tabular}{|l|c|c|}
\hline \multirow{5}{*}{ Component } & \multicolumn{2}{|c|}{$\begin{array}{r}\text { Measurement values compared to limitations } \\
\text { described in the maintenance manuals } \\
\checkmark: \text { Within the safe limit } \\
\times \text { : Outside of safe limit }\end{array}$} \\
\cline { 2 - 3 } & $\begin{array}{c}|c| \\
\text { Vibration monitoring } \\
\text { before torquemeter } \\
\text { shaft replacement }\end{array}$ & $\begin{array}{c}\text { Vibration monitoring } \\
\text { after torquemeter } \\
\text { shaft replacement }\end{array}$ \\
\hline Propeller & $\checkmark$ & $\checkmark$ \\
\hline Gearbox & $\times$ & $\checkmark$ \\
\hline Compressor & $\times$ & $\checkmark$ \\
\hline Turbine & $\checkmark$ & $\checkmark$ \\
\hline
\end{tabular}

the bleed air system, based on the engine's architecture the engine's structural health condition was investigated. Excessive vibrations can cause structural damage to other engine components. By measuring the vibration levels and comparing them with the recommended safe limits, it was verified that the faults in the starting system components were caused by excessive vibrations.

It was proven that following the instructions in the technical manuals and by using velocity transducers, excessive vibrations can be successfully detected. Also, the velocity transducers connected to each module are not able to isolate a vibration fault to its corresponding component. In the case study described, even though the transducers mounted at the gearbox and the compressor capture vibration values are above the limit, neither the gearbox nor the compressor were responsible for the fault. Furthermore, the existence of a mechanical fault at an engine's module (torque meter shaft) transfers its effect and causes excessive vibrations to adjacent modules (gearbox, compressor) that are connected. This phenomenon encases the danger that adjacent components become degraded and cause engine faults. Finally, a mechanical fault existed at the torque meter shaft, despite the fact that excessive vibrations did not affect the engine's thermodynamic characteristics. Values of pressure, temperature, and mass flow through the engine's gas turbine did not exceed their nominal limits, even though the engine suffered from excessive vibrations.

\section{Conclusions}

After a failure to start the engine, the steps described in the FIM provided by the Original Equipment Manufacturer (OEM) are followed. Based on these steps, the pneumatic starter was replaced, and the engine could start normally. The repeated unsuccessful attempts at a very short period led to the conclusion that the root cause was not related to the starting system components. An investigation of the engine's vibration characteristics indicated that a fault in the torque meter shaft caused excessive vibrations which subsequently caused the starter motor and flexible duct failures. The fault isolation reasoning required in this case study had to go beyond standard troubleshooting actions. 
Engineering reasoning based on the interactions of the system were applied in order to isolate the root cause of the observed failure mode. Fault repeatability in a short period of time created an alert for increased awareness. Due to the fact that this is a legacy system, engine vibrations are not monitored during normal engine operation. This makes the suspicion of excessive engine vibrations more challenging. Finally, this case study demonstrates the fact that an engineering understanding of the system under investigation contributes critically to successful fault diagnosis.

\section{Disclosure statement}

The author declares no conflict of interests.

\section{References}

Cubillo, A., Perinpanayagam, S. \& Esperon-Miguez, M. (2016). A review of physics-based models in prognostics: application to gears and bearings of rotating machinery. Advances in $\mathrm{Me}$ chanical Engineering, 8(8), 1-21. https://doi.org/10.1177/1687814016664660

Djaidir, B., Hafaifa, A., \& Kouzou, A. (2017). Faults detection in gas turbine rotor using vibration analysis under varying conditions. Journal of Theoretical and Applied Mechanics, 2014, 393. https://doi.org/10.15632/jtam-pl.55.2.393

Durkin, J. (1994). Expert systems: design and development. New York: Macmillan Publishing Company.

Evan, C. P. (2012). Industrial internet: pushing the boundaries of minds and machines - general electric. Imagination at work. http://www.ge.com/docs/chapters/Industrial_Internet.pdf

Fedoronchak, T., \& Kolpakova, T. (2018). Study on vibrations diagnostics of gas turbine engines with wavelets. In Modern Problems of Radio Engineering, Telecommunications and Computer Science, International Conference, 6, 4. Lviv-Slavske, Ukraine: IEEE. https://doi.org/10.1109/TCSET.2018.8336348

Gao, Z., Cunbao, M., Dong, S., \& Yang, L. (2017). Deep quantum inspired neural network with application to aircraft fuel system fault diagnosis. Neurocomputing, 238(C), 13-23.

https://doi.org/10.1016/j.neucom.2017.01.032

Haidong, S., Jiang, H., Zhao, K., Wei, D., \& Li, X. (2018). A novel tracking deep wavelet auto-encoder method for intelligent fault diagnosis of electric locomotive bearings. Mechanical Systems and Signal Processing, 110, 193-209. https://doi.org/10.1016/j.ymssp.2018.03.011

Hu, Q., Aisong, Q., Qinghua, Z., Jun, H., \& Guoxi, S. (2018). Fault diagnosis based on weighted extreme learning machine with wavelet packet decomposition and KPCA. IEEE Sensors Journal, PP(c), 1-1. https://doi.org/10.1109/JSEN.2018.2866708

Hungate, D. (1979). Lockheed Martin: service news. LockheedGeorgia Company.

Hwang, I., Sungwan, K., Youdan, K., Chze Eng, S. (2010). A survey of fault detection, isolation, and reconfiguration methods. IEEE Transactions on Control Systems Technology, 18(3), 636-653. https://doi.org/10.1109/TCST.2009.2026285
Jackson, P. (ed.). (1997). Jane's all the world's aircraft (87th ed.). Jane's Information Group.

Jennions, I. K. (ed.). (2011). Integrated vehicle health management - perspectives on an emerging field. SAE International. https://doi.org/10.4271/R-405

Jia, F., Yaguo, L., Na, L., \& Saibo, X. (2018). Deep normalized convolutional neural network for imbalanced fault classification of machinery and its understanding via visualization. Mechanical Systems and Signal Processing, 110, 349-67. https://doi.org/10.1016/j.ymssp.2018.03.025

Kleer, J. De, \& Kurien, J. (2003). Fundamentals of model-based diagnosis. IFAC Proceedings Volumes (IFAC-Papers Online), 6670 (June 2003), 25. https://doi.org/10.1016/S1474-6670(17)36467-4

Milne, D., Pen, L., Thompson, D., \& Powrie W. (2018). Automated processing of railway track deflection signals obtained from velocity and acceleration measurements. Proceedings of the Institution of Mechanical Engineers, Part F: Journal of Rail and Rapid Transit, 232(8), 2097-2110. https://doi.org/10.1177/0954409718762172

Mirsaitov, F., \& Ignatkov, K. A. (2018). Gas turbine engine in-flight diagnostics using 3D vibration spectra. Proceedings - 2018 Ural Symposium on Biomedical Engineering, $\mathrm{Ra}$ dioelectronics and Information Technology, USBEREIT 2018, 275-278. https://doi.org/10.1109/USBEREIT.2018.8384603

Mobley, R. K. (2002). An introduction to predictive maintenance. Elsevier. https://doi.org/10.1016/B978-075067531-4/50006-3

Muhammad, M., Masdi, B., Sarwar, U., Tahan, M. R., \& Karim, A. (2016). Fault diagnostic model for rotating machinery based on principal component analysis and neural network. ARPN Journal of Engineering and Applied Sciences, 11(24), 14327-14331.

Nivesrangsan, P. (2018). Bearing fault monitoring by comparison with main bearing frequency components using vibration signal. In 2018 5th International Conference on Business and Industrial Research (ICBIR) (pp. 292-296). https://doi.org/10.1109/ICBIR.2018.8391209

Saha, B., \& Vachtsevanos, G. (2006). A model-based reasoning approach to system fault diagnosis. In Proceedings of the 10th WSEAS International Conference on Systems, 2006, 64-71. http://dl.acm.org/citation.cfm?id=1984211.1984224

Silva, A., Zarzo, A., Munoz-Guijosa, J. M., \& Miniello, F. (2018). Evaluation of the continuous wavelet transform for detection of single-point rub in aeroderivative gas turbines with accelerometers. Sensors (Switzerland), 18(6), 1-22. https://doi.org/10.3390/s18061931

Teng, W., Ding, X., Zhang, X., Liu, Y., \& Ma, Z. (2016). Multifault detection and failure analysis of wind turbine gearbox using complex wavelet transform. Renewable Energy, 93, 591598. https://doi.org/10.1016/j.renene.2016.03.025

Vachtsevanos, G., Lewis, F., Roemer, M. J., Hess, A., \& Wu, B. (2006). Intelligent fault diagnosis and prognosis for engineering systems. John Wiley \& Sons, Inc. https://doi.org/10.1002/9780470117842

Walsh, P. P., \& Fletcher, P. (2004). Gas turbine performance. Blackwell Science Ltd. https://doi.org/10.1002/9780470774533 